\title{
Smart Grids and Machine Learning in Chinese and Western Intellectual Property Law
}

\section{The Key Role of Machine Learning in Integrating Sustainable Energy into Smart Grids and the Corresponding Approaches to Asset Protection in Intellectual Property Law}

\section{Stefan Papastefanou}

Accepted: 4 August 2021/Published online: 30 August 2021

(C) The Author(s) 2021

\begin{abstract}
Having huge power grids successfully integrate sustainable energy sources requires a smart and flexible power grid management system. Such smart systems have to adapt fast and accurately to a great amount of data input - a task which is made easier by applying modern machine learning technology. Solutions crafted by dynamic and powerful computing algorithms have the potential to surpass human cognitive capabilities. The question arises whether and how intellectual property law can be used to set the right incentives. This paper initially describes the basic functions of smart grids and the corresponding necessity of machine learning. Subsequently, it will analyze the current approaches of the most relevant patent offices in dealing with the challenges of AI-related smart grid inventions. Ultimately, it will be demonstrated that the contemporary discussions fail to focus on practical considerations of market entry possibilities that might be more promising than the approach of creating new exclusionary intellectual property rights.
\end{abstract}

Keywords Machine learning · Smart grid - Patent law - Copyright law · AI · Compulsory licensing

\section{Basic Functions of Smart Grids}

The term "intelligent power grid" describes the communicative connection of the actors in the energy system from generation to transport, storage and distribution to

Stefan Papastefanou is a lecturer at Bucerius Law School, Center for Transnational IP, Media and Technology Law and Policy, Hamburg, Germany, as well as a research fellow at the Singapore Management University, Applied Research Centre for Intellectual Assets and the Law in Asia, Singapore.

S. Papastefanou $(\bowtie)$

LL.B.; Lecturer at Bucerius Law School, Center for Transnational IP, Media and Technology Law and Policy, Hamburg, Germany

e-mail: stefan.papastefanou@law-school.de 
consumption in an energy supply network. Such an integrated data and energy network is equipped with completely new structures and functionalities, with a special focus on the successful integration of "renewable" 1 energies. Since renewable energies are often characterized by fluctuating circumstances such as sunshine or wind, feeding them in increases the risk of unstable grid conditions and power fluctuations. Smart network operators can gain knowledge and control over the feed-in and thus increase the share of renewable energies. This shows that a successful implementation requires the handling of large amounts of data in a short time, so that an "intelligent system" and considerable computing power are required.

However, the central goal of smart grid initiatives is to significantly increase the share of renewable energies. Hence, it is important to predict future renewable energy production as the grid must send out generators to meet demand when production varies. While manual development of sophisticated predictive models for large solar parks may be possible, developing these models for distributed generation in millions of households across the grid is a difficult challenge. Such a challenge can be met by introducing a computer-based solution.

For example, the automatic creation of location-specific forecast models for solar power generation from weather forecasts of the National Weather Service (NWS) is carried out with the help of machine learning techniques. When feeding solar power into a smart grid, such forecast models are essential in order to be prepared for potential fluctuations. In the case of the NWS, several regression techniques for generating prediction models were compared and it was shown that machinelearning-based prediction models are considerably more accurate than existing prediction models. $^{2}$

Another synergy effect can be found in the coupling between electricity and natural gas networks and the use of intelligent communication technologies in order to achieve more efficient energy management. ${ }^{3}$ Here, solutions for fluctuations in the power grid are also predicted using machine learning processes and "smoothed" by adjusting feed-in and storage in overall consumption. The very terms of "smart" grid and "intelligent" power grid indicate that this area of engineering is a prime suspect for machine learning and artificial intelligence. Naturally, the effect of smart grids is greatest within countries that have an increasing demand for electric energy.

\section{Rising Significance of Smart Grids in China}

While the energy grid situation and corresponding approaches to include more "clean" or sustainable energy in the EU have been the subject of political discussion for a significant amount of time, it is helpful to look at the recent developments in China and its challenges to put things into perspective.

\footnotetext{
${ }^{1}$ Even though it is physically impossible for energy to be "renewable", the term is still used within this paper, since it is widely used - even in scientific discourse.

2 Sharma, Sharma, Irwin and Shenoy (2011), p. 528 et seq.

3 Sheikhi, Rayati and Ranjbar (2015), p. 34 et seq.
} 
The central government, which includes a significant involvement by Chinese state-owned enterprises (SOEs), heavily regulates the power industry in China. The concept of smart grid development started in 2009. The intent then was to build a capable and reliant electricity network with ultra-high voltage (UHV) transmission corridors.

While environmental protection was part of the original concept, the goals of economic growth and electricity supply to remote regions became the more significant drivers for smart grid development. Consequently, the construction of smart grids was mainly focused on a provincial level. ${ }^{4}$ During the decade-long investment and development, SOEs have gained experience in UHV transmission and smart sub-stations. The Chinese government has expressed its ambition to become the world leader in electrical power equipment by 2025 as part of the national strategy outlined in the Technology Roadmap ${ }^{5}$ (2017) of the Made in China 2025 programme. ${ }^{6}$ The Made in China 2025 programme focuses significantly on innovation and technology. With this programme come large amounts of state funding to incentivize development. Becoming the world's largest market for electricity infrastructure development and smart technologies is also an ambitious goal. In this context, China offers business opportunities to small and medium-sized enterprises (SMEs) with corresponding products and intellectual property. Such opportunities are usually linked to smart distribution networks and multi-energy integration. A survey conducted for Swedish SMEs showed that China is a highly relevant market. However, the study also highlighted that China is a challenging market to enter due to high market entry costs, corruption and state interference, as well as a lack of standards. Especially the monopolized structure of the Chinese power industry is deterring foreign investors. A combination of both state-owned companies and private power plants produce energy; however, power transmission, distribution and retail remain vertically integrated and monopolized by the two major grid companies: State Grid Corporation of China (SGCC) and the China Southern Power Grid Co., Ltd. (CSG). ${ }^{7}$

Additionally, China has been suffering from serious environmental pollution caused by a fossil fuel dominant energy supply. ${ }^{8}$ The implementation of a smart grid system might be a solution to integrating renewable energy into the power system and thereby increasing energy efficiency, adapting to changes in the power consumption structure of electric vehicles and distributed generation, as well as reducing pollution. SGCC and CSG put forward smart grid development plans as early as 2009. According to a plan by National Energy Agency, by the end of 2020

\footnotetext{
${ }^{4}$ U.S. Energy Information Administration (2020), p. 13 et seq.; Smart Grid Market Analysis: China, WSP 2019, 4; China Smart Grid Network Market - Growth, Trends, and Forecasts (2020-2025), 4.1 China Power Market Introduction.

5 Smart Grid Market Analysis: China, WSP 2019, 5; China Smart Grid Network Market - Growth, Trends, and Forecasts (2020-2025), 4.5 Evolution of China Smart Grid System.

${ }^{6}$ China Smart Grid Network Market - Growth, Trends, and Forecasts (2020-2025), 4.6 Market Size and Demand Forecast in US\$ million, until 2025; Market Overview; Smart Grid Market Analysis: China, WSP 2019, 5.

7 Fu, Zhao and Guo (2012), p. 330 et seq.

${ }^{8} \mathrm{Yu}$, Yang and Chen, MDPI Energies 2012, p. 1321 et seq.
} 
the accumulated investment in the smart grid shall have reached RMB 4 trillion. ${ }^{9}$ However, local suppliers, especially the companies affiliated with the power company groups, are favoured and it is common that the government supports local suppliers and local production. Consequently, Chinese companies have substantial shares of the market in the smart grid sector. ${ }^{10}$

The Made in China 2025 initiative is the country's first action plan focusing on promoting manufacturing. Industry experts say that more efforts are required in order to remove the bottlenecks of key components and to achieve world-leader status. ${ }^{11}$ In September 2015, China's president gave a speech to advocate the building of a global energy internet, named Global Energy Interconnection (GEI), through a massive electricity grid that would distribute renewable energy across the world. ${ }^{12}$ The energy internet is an important element of the Made in China 2025 initiative, and the State Grid Corporation plans to leverage its domestic experience to export its technology and equipment abroad to build an energy infrastructure including power generation facilities, transmission networks and energy transportation assets, covering many countries. ${ }^{13}$

Addressing such a challenge requires a well-tuned smart grid, which in turn is based on a complex application of machine learning and the corresponding algorithms.

\section{Machine Learning in the Context of Smart Grids}

In order to clarify which individual effects machine learning can have in energy systems and which particularities must also be dealt with legally, it is first necessary to illustrate the basic systems of machine learning.

\subsection{Machine-Learning Fundamentals}

Machine learning serves to teach a program to develop independent solutions so that complex and abstract tasks can be solved by it. The aim is to give the program "learning ability". The success of Artificial Intelligence (AI) is considerable and the hopes for future improvements even higher, even so far as introducing the "fourth industrial revolution". ${ }^{14}$

\footnotetext{
9 Smart Grid Market Analysis: China, WSP 2019, 4 ( 600 billion US\$) - most recent data available.

${ }^{10} \mathrm{Fu}$, Zhao and Guo (2012), p. 331 et seq.; China Smart Grid Network Market - Growth, Trends, and Forecasts (2020-2025), 4.6 Market Size and Demand Forecast in US\$ million, until 2025, 4.7 Recent Trends and Developments; National Bureau of Statistics of China, Statistical Communiqué of the People's Republic of China on the 2019 National Economic and Social Development, 2020, p. 4 et seq.

11 Smart Grid Market Analysis: China, WSP 2019, 6; China Smart Grid Network Market - Growth, Trends, and Forecasts (2020-2025), 4.8 Smart Grid Government Policies, Targets, and Regulations.

12 Smart Grid Market Analysis: China, WSP 2019, 8; China Smart Grid Network Market - Growth, Trends, and Forecasts (2020-2025), 4. Market Overview.

13 China Smart Grid Network Market - Growth, Trends, and Forecasts (2020-2025), 4.10 Supply Chain Analysis; Smart Grid Market Analysis: China, WSP 2019, 8.

14 Nägerl, Neuburger and Steinbach (2019), p. 336.
} 
One precise definition - legal or technological - of what artificial intelligence is does not exist. Usually, scholars refer to the 1956 definition, when the concept of AI was first the subject of a computer science conference: "the science and engineering of making intelligent machines". ${ }^{15}$ However, that definition does not help with the emerging legal challenges, because it focuses on the process of creating AI rather than the AI itself. This lack of precision poses a challenge for legal discussion. Within legal literature, there have been many attempts to define or characterize AI usually with results that leave a lot to be desired. ${ }^{16}$ For the purposes of this paper and simplicity's sake, the definition will be based on the distinction of AI and algorithms. ${ }^{17}$ This distinction allows understanding what significant developments in IT transform a simple computer program or algorithm into AI. An algorithm is a logical system that can be executed by technical devices and follows a strict order of operations that allow for a certain output depending on a specific input: a very basic "if - then" operator. ${ }^{18}$ The term AI goes beyond that - an algorithm is almost never an AI, even though an AI might exist in the form of an algorithm. It is best to imagine the AI to be the method by which an algorithm can be created - not by a human programmer but by an artificial one. Hence, the ability to create, modify, test and optimize algorithms characterizes AI. ${ }^{19}$ It is not necessary for AI to have more advanced cognitive abilities than a human ${ }^{20}$ but rather to make use of the computing power and storage capabilities of technology, which are already far superior to any human mind. ${ }^{21}$

\footnotetext{
15 McCarthy, Minsky, Rochester and Shannon (1955), p. 48.

${ }^{16}$ Lauber-Rönsberg (2019), p. 244, for example provides no definition or distinction at all. With a good effort but still falling short of the actual necessary distinction: Ménière and Pihlajamaa (2019), p. 332, "an algorithm [that] changes" which is correct. However, there is no clear distinction between different kinds of inventions and the inclusion of a "strong AI" that is capable of passing the Turing test (a test of a machine's ability to exhibit intelligent behaviour equivalent to, or indistinguishable from, that of a human) which is difficult as how an AI-assisted invention is created is not described, i.e. by what means
} the target algorithm is changed through AI.

${ }^{17}$ As an example of the possible confusion when failing to adhere to this basic distinction: Nägerl, Neuburger and Steinbach (2019), p. 336, where AI is defined as being able to "perceive its environment and uses measures to maximize its change for successfully achieving its objectives". Such a definition is not correct because that description also fits an advanced but still traditional algorithm. It does not include the learning or adapting capabilities of a program.

18 Also with a confusing definition: Wang (2017), p. 150, who characterizes AI-generated contents as "the result of the application of algorithms, rules and templates". This is incorrect because AI is not the result but rather the method by which such results can be achieved. Also describing "the learning process as 'the course of identifying rules" is incorrect. He further states that: "If applying the same algorithm set on different terminals on the same object, all will render the same result, then no matter how 'creative' the AI-generated content appears, it is unoriginal, as the result is definite". Most AI systems include randomly generated elements, thereby making their results unpredictable and not "definite".

19 Schmidt, Marques, Botti and Marques (2019), p. 1 et seq.

${ }^{20}$ Usually called "strong AIs" and currently only theoretical. Still, Dornis (2019), p. 1252, uses this definition: "An AI able to create without direct human influence or influenced by specifications in the programming" - such an AI does not currently exist, since every current version of AI can be traced back to specifications in the programming.

${ }^{21}$ Using this definition: Ory and Sorge (2019), p. 712, "to solve problems to be priorly thought only solvable by humans". This is incorrect, because it does not cover problems that were not solvable by 
To achieve the effect of learning or adapting within an entity that is not human is an immense task. Therefore, one of the most convenient ideas to create AI came from copying biological principles. If we copy what makes humans smart, we can create smart machines. One method focuses on following the source of individual human intelligence - the brain. The artificial neural network or Neural Network Method is one of the most popular approaches in machine learning. A neural network is a connection-oriented approach that is inspired by the way the brain's neurons are wired and interact. An artificial neural network consists of a number of nodes (neurons) that are connected by edges. ${ }^{22}$

Genetic Breeding Models ${ }^{23}$ on the other hand are based on a reference to the evolution of natural living beings and imitate the evolutionary process of developing and increasing capabilities and adaptability over generations.

The decisive factor for all forms of machine learning is the fact that the end product, the so-called target algorithm, is developed independently by the machine learning environment and even the developers do not know how exactly the problem is solved, even if individual lines of code or code clusters are still accessible to human comprehension. It is also highly relevant for the legal assessment that an algorithm developed by AI requires significant amounts of specific training data and is usually created in object code rather than source code. ${ }^{24}$

\subsection{Specific Functions and Applications of Machine Learning}

Individual solutions that are produced by such a target algorithm can also be found in numerous smart grid initiatives. For example, attack detection problems in a smart grid are also called "statistical learning problems", in which measurements in batch or online settings of a given power grid have to be observed and analyzed to identify an attack. As is usual with identification problems, machine learning algorithms are used to classify measurements as safe or attacked. An intrusion detection framework is provided to take advantage of all available prior knowledge of the system and to overcome limitations resulting from the small structure of the problem in the respective approach. The relationships between statistical and geometric properties of the attack vectors and learning algorithms used in the attack scenarios are analyzed in order to detect non-observable attacks with the help of statistical learning methods. ${ }^{25}$ Again, the machine is better suited for these tasks because of its computing power and speed.

New attacks (so-called stealth attacks) that cannot be detected with the conventional detection of faulty data using the state estimation have also been

Footnote 21 continued

humans. This is especially relevant in the context of smart grid systems, because those are only made possible with computing power that humans do not possess.

22 With a comprehensive overview: Ehringer and Stiemerling (2018), p. 761 et seq.

23 With a description of the basic principles and functions: Papastefanou (2019), p. 210 et seq.

24 Ménière and Pihlajamaa (2019), p. 335; Nägerl, Neuburger and Steinbach (2019), p. 341.

25 Ozay, Esnaola, Vural, Kulkarni and Poor (2015), p. 1773 et seq. 
countered with a similar success rate. ${ }^{26}$ This is achievable by the "adapting" factor of AI, which makes it possible to detect new patterns in so-far unknown attack formats.

It is precisely in such a cyber-attack on an energy system where human judgment proves to be less reliable, since attempts are made to disguise the attack and deceive the operator about the actual state of the system. ${ }^{27}$ An algorithm that adapts in real time and can access all available data is much harder to deceive.

In addition to the possibilities for the security of the energy network, there are also advantages for consumers. In particular, the visualization of consumption patterns ${ }^{28}$ and detailed consumption statistics in the smart grid $^{29}$ are the basis for better insight for consumers into their own electricity consumption and the associated possibilities for more efficient electricity use or for saving electricity.

The concept of the "intelligent home" is also made possible in two ways through machine learning processes. It is possible to switch from traditional households with advanced measurement infrastructure to intelligent units with immediate and distributive decision-making options using algorithm-based forecasting methods, smoothing peak demand curves and thus reducing costs. ${ }^{30}$

Ultimately, in addition to the central goal of creating a flexible energy supply structure for sustainable energies, machine learning offers protection against attacks on energy systems and can reduce costs for the consumer. However, in order for the development of these systems to be worthwhile, the legal framework for their possible protection as intellectual property has to be analyzed.

\section{Legal Challenges of Implementing AI in Smart Grids}

There are numerous legal challenges in the classification and protection of machine learning systems and the corresponding target algorithms or other creations in intellectual property law. Both Western and Chinese administrative offices have issued guidelines specifically dealing with inventions in the context of machine learning. Smart grids work as a perfect example in showing how the new patentability guidelines are applied to software and the possibility of conferring technical character to computer programs.

\subsection{Machine Learning in Western Patent Law}

Patent law generally protects inventions; therefore models and algorithms that have a "mathematical character per se" are as such excluded from patentability, regardless of the specific model used - unless they are implemented in an otherwise technical invention. The reason for this restriction is the intent to impose meaningful

\footnotetext{
${ }^{26}$ Esmalifalak, Liu, Nguyen, Zheng and Han (2014), p. 1644 et seq.

27 Hink, Beaver, Buckner, Morris, Adhikari and Pan (2014), p. 104 et seq.

28 Simmhan, Aman, Kumbhare, Liu, Stevens, Zhou and Prasanna (2013), p. 1538 et seq.

29 Jiang, Zhang, Ren, Han, Chen and Hanzo (2016), p. 98 et seq.

${ }^{30} \mathrm{Li}$ and Sudharman (2014), p. 1529 et seq.
} 
limits on an otherwise extremely broad patent claim. This so-called technicality can, however, be satisfied by a reference to a technical process in which the algorithm is used.

\subsubsection{The European Approach: Technical Character and Technical Effect}

In 2019, the European Patent Office (EPO) published guidelines on patentability for machine learning and general AI systems. ${ }^{31}$

In particular, the EPO stated: "Terms such as 'support vector machine', 'reasoning engine' or 'neural network' [a form of machine learning] may, depending on the context, merely refer to abstract models or algorithms and thus do not, on their own, necessarily imply the use of a technical means". This approach is very practical as it focuses on literal terms within a patent application to determine patentability. The EPO instructs its examiners to carefully look at these expressions. Such a method - mainly advising the patent examiner - highlights the difficulty of defining and dealing with AI.

If a machine learning target algorithm is only used to automatically classify data, a patent application is not possible due to a lack of technicality or further technical use. The same applies to the automatic control of a printing press, which is characterized by the use of a linear regression analysis in order to correlate subjective and objective harmonic analysis data with regard to the print quality and to obtain regression parameters. Once these parameters are learned, they can be used to predict the subjective data based on the objective data obtained. This method is inventive only when this data is applied to a specific problem. Nevertheless, even such an application can be excluded from patenting if the described features for classifying data sets are classified as an obvious solution. ${ }^{32}$

The protection requirements for inventions that focus on machine learning results are therefore relatively high. These requirements under the EPO's guidelines pay close attention to whether a claimed invention has technical character. ${ }^{33}$ Because of the newly added subsection within the guidelines regarding mathematical methods, determining the eligibility of mathematical methods might be similar to the method of assessing the patentability of computational models and algorithms, which are key components of AI-related inventions. Consequently, a patent claim would be deemed unfit for patentability if it describes a purely abstract mathematical method and does not involve any technical means in its desired results.

Patentability is generally possible if the claim describes either a method involving the algorithm in a technical device (such as a computer or processing unit) or a device where the entire subject matter has a technical character. As indicated by the EPO's guidelines, the technical character of an invention means it produces a "further technical effect" that serves a technical purpose by its application to a field

\footnotetext{
31 EPO Guidelines for Examination 2019, Part G, Chapter II, Art. 3.3.1 - Artificial intelligence and machine learning.

32 EPA T 1148/05.

33 EPO Guidelines for Examination 2019, Part G, Chapter II, Art. 3.3.1.
} 
of technology and/or by being adapted to a specific technical implementation. ${ }^{34}$ The key feature of a technical application is that it serves a technical purpose, which must be specific. This means that a generic purpose such as "controlling a technical system" is insufficient to grant technical character to a mathematical method. ${ }^{35}$ Where a claim describes a specific technical implementation of a mathematical method, the mathematical method may still contribute to the technical character of the invention. This is possible even if it is independent of any technical application. $^{36}$

One of the most significant challenges of such an implementation is the necessity that the contribution of the algorithm has to be more than mathematical, such as faster computational speed. To be eligible for patent protection, the algorithm must be specifically linked to the technical purpose and be part of the "technical considerations". ${ }^{37}$ Examples given in the EPO guidelines for a "further technical effect" are computer programs that specify a method of controlling an anti-lock braking system in a car, determining emissions by an X-ray device, compressing video, restoring a distorted digital image, or encrypting electronic communications - provided they run on a computer. ${ }^{38}$

\subsubsection{Technical Character of AI in Smart Grids}

In the context of smart grids, a technical or practical implementation is usually achievable. Since the AI would run on a complex system of computers and access electric control and measuring devices, the application of the algorithms created by the AI go beyond the "normal" physical interactions between the program and the computer on which it is run. According to the EPO guidelines, the normal physical effects of the execution of a program are the circulation of electrical currents in the computer which are insufficient to confer technical character to a computer program. ${ }^{39}$ Specifically, the control of a technical process or of the internal functioning of the computer itself or its interfaces is considered to be a further technical effect. Most likely, the systems to control a power grid are already based on a computer program which runs algorithms and has a human interface in place. However, transforming it into a smart version is different from simply installing a computer program serving a non-technical purpose requiring less computing time than a prior-art program serving the same non-technical purpose. ${ }^{40}$ In practice, a smart grid system requires new hardware implementations such as measuring tools and control interfaces that can be accessed by AI. In addition, a smart grid approach falls under the category of an implemented invention, because some features of the smart grid are based on computer networks wherein the features are realized by

\footnotetext{
${ }^{34}$ EPO Guidelines for Examination 2019, Part G, Chapter II, Art. 3.6.

35 EPO Guidelines for Examination 2019, Part G, Chapter II, Art. 3.3.1.

36 EPO T 1358/09 (Classification/BDGB Enterprise Software) of 21 November 2014.

37 Landscheidt and Bethge (2019), p. 778.

38 EPO Guidelines for Examination 2019, Part G, Chapter II, Art. 3.6.1.

39 EPO Guidelines for Examination 2019, Part G, Chapter II, Art. 3.6.

40 See T 1227/05, T 1784/06 and T 1370/11.
} 
means of a computer program. The existing controls of power grids are usually unable to allow for the flexible and quick changes that a smart grid requires:

(a) To distribute energy from sustainable energy sources and collect data about the flow and spikes in energy consumption require a large amount of data and a quick response time between the devices used in the smart grid. These devices control the technical process of identifying and predicting energy demand. Especially the element of prediction of energy spikes in real time based on a live analysis of data is entirely new to the technical process. Therefore, this aspect of controlling the technical process of energy distribution has to be considered a "further technical effect". In addition, this feature of the smart grid is based on a complex network of programmable devices that are realized in their execution by a computer program. The program can be created by AI.

(b) Similarly, the identification of attack patterns is a "further technical effect" and also implemented in the smart grid by means of a computer program. Identifying attack patterns requires the AI to access all information about possible entry points of electric energy into the system and output data. The information is then processed and allows the AI to learn what an unauthorized feed-in or output might look like. By providing the AI with the controls to the power production and transfer lines to stop such attacks, again, the technical process is controlled by the program. This novel feature of automated and adaptive cyber-attack protection is furthermore realized by means of a computer program and is therefore sufficient to confer technical character to the AI solution.

(c) Finally, the integration of individual households generally renders the smart grid systems viable for patent protection. The integration requires individual households to be equipped with smart appliances that measure energy consumption but also have means to control energy intake and distribution. Those controls and measurements are also an important element to provide the smart grid AI with the data necessary to learn to execute its aforementioned tasks of efficiently including sustainable energy and learning cyber-attack patterns. Establishing a network between these individual devices in individual households and the power grid control stations is another feature that is realized by means of a computer program and controls the technical process of the system itself.

In conclusion, it is almost certain that the implementation of smart grids on a larger scale with corresponding hardware updates and control processes fulfils the requirements of patentability under EU law. There are also some uncertainties: If AI is included in the smart grid process only in the creation of the algorithm that is ultimately implemented in the smart grid solution, the AI itself fails to meet the requirement of (a) controlling the technical process, since it does not play a part in executing the algorithm or (b) enabling the implementation of a feature that is realized by means of a computer program, because the AI itself is not the computer program that realizes the feature. The use of AI in this way may very well be necessary for the realization of the smart grid as a whole but is not producing a technical effect. 


\subsubsection{Patentability in the US: The Alice/Mayo Test}

In comparison, the USPTO revised its Patent Subject Matter Eligibility Guidance in January 2019 regarding whether subject matter is patent-eligible or not. Even though the amendments are not specifically for AI-related inventions, the revised manual provides some guidance on how to determine the patent-eligibility of AIrelated inventions. ${ }^{41}$ It starts by addressing the patent claim and whether it falls into one of the three categories of abstract ideas, namely, mathematical concepts, certain methods of organizing human activity, and mental processes. If affirmed, examiners will then determine whether the abstract idea embodied in a claim is integrated into a practical application. ${ }^{42}$ Similar to the EPO guidelines, examiners are instructed to consider whether the claim integrates the abstract idea into a practical application that imposes significant and meaningful limits on the mathematical concept. This approach ensures that the applicant is unable to monopolize the abstract idea or concept. Such limitations that are indicative of a necessary integration into a practical application include improvements to the functioning of a computer or to another technology or technical field, use or application of a particular machine, and effecting a transformation or reduction of a particular article to a different state or thing. ${ }^{43}$ Generally, applying or using the abstract idea in some other way beyond generally linking it to a technological environment is required to ensure patentability. However, this concept is different to the EPO concept of "technical means" or "achieving technical character".

As part of the patent subject matter eligibility test of the USPTO, softwarerelated inventions are subjected to the strict Alice/Mayo two-part test. The first part of the test is to determine whether patent claims are directed to an abstract idea, a law of nature or a natural phenomenon. ${ }^{44}$ In case the claims are directed to such judicial exceptions, in a second step it is determined whether the claims recite additional elements that amount to significantly more than the judicial exception. ${ }^{45}$ This second part is also called the "search for an "inventive concept" 46 and becomes especially relevant for software-related inventions. It supersedes ${ }^{47}$ the "special purpose computer" test, which postulated the rationale that an otherwise

\footnotetext{
${ }^{41} \mathrm{Xu}$, "How to Determine the Examination Standards for the Subject Matter of AI-related Inventions?", China Intellectual Property Newspaper (Beijing, 8 December 2019).

${ }^{42}$ USPTO guidance revised in January 2019 also defines mathematical concepts as "mathematical relationships, mathematical formulas or equations, and mathematical calculations". 2019 Revised Patent Subject Matter Eligibility Guidance (2019 PEG).

${ }^{43}$ EPO T 1358/09 (Classification/BDGB Enterprise Software) of 21 November 2014.

${ }^{44}$ United States Supreme Court, Mayo Collaborative Servs. v. Prometheus Labs., Inc., 566 U.S. 66, 71, 101 USPQ2d 1961, 1965 (2012).

${ }^{45}$ United States Supreme Court, Mayo Collaborative Servs. v. Prometheus Labs., Inc., 566 U.S. 66, 71, 101 USPQ2d 1961, 1966 (2012).

${ }^{46}$ United States Supreme Court, Alice Corp. Pty. Ltd. v. CLS Bank Int'l, 573 U.S. 208, 216, 110 USPQ2d 1976, 1981 (2014).

${ }^{47}$ Eon Corp. IP Holdings LLC v. AT\&T Mobility LLC, 785 F.3d 616, 623, 114 USPQ2d 1711, 1715 (Fed. Cir. 2015) ("[W]e note that Alappat has been superseded by Bilski, 561 U.S. at 605-06, and Alice Corp. v. CLS Bank Int'l, 573 U.S. 208, 110 USPQ2d 1976 (2014)”).
} 
ineligible algorithm or software could be made patent-eligible by merely adding a generic computer to the claim for the "special purpose" of executing the algorithm or software. ${ }^{48}$ This superseded test seems closer to the EPO approach and considerably stricter. ${ }^{49}$ Since software as an algorithm does fall under the judicial exception of an abstract idea in the first part of the test, it is necessary to provide additional elements that go significantly beyond said exception. In the context of US patent law, it is particular harmful to patent-eligibility if a software claim is merely amended by adding a generic computer or generic computer components, even if the generic computer is "specially programmed" or is a "particular machine". 50 One way to achieve "significantly more than the judicial exception" is to integrate the exception into a practical application. ${ }^{51}$ In other words, the claimed method must be tied to a particular machine, which means that the machine must "play a significant part in permitting the claimed method to be performed, rather than function solely as an obvious mechanism for permitting a solution to be achieved more quickly". 52 This so-called "extra-solution activity" is present in patent claims where the use of a machine only contributes nominally or insignificantly to the execution of the claimed method. ${ }^{53}$ Claims that include well-understood, routine, conventional activities previously known to the industry as additional elements are also considered less likely for patent-eligibility. Examples for such activities were claims reciting naturally occurring correlations of thiopurine metabolite blood concentrations and efficacy of drug dosages along with telling a doctor to measure such concentrations using any known process. ${ }^{54}$ This was considered to be non-eligible because doctors "routinely measured metabolites as part of their investigations into the relationships between metabolite levels and efficacy and toxicity of thiopurine compounds". 55 On the other hand, modifying conventional internet hyperlink protocol to dynamically produce a dual-source hybrid webpage was considered eligible because this approach differed from the conventional operation of internet hyperlink protocol that transports the user away from the host's webpage to the third party's webpage. ${ }^{56}$ Generally speaking, the standards for well-understood, routine,

\footnotetext{
48 Originally: In re Alappat, 33 F.3d 1526, 31 USPQ2d 1545 (Fed. Cir. 1994).

49 Intellectual Ventures I LLC v. Capital One Bank (USA), N.A., 792 F.3d 1363, 1366, 115 USPQ2d 1636, 1639 (Fed. Cir. 2015) ("An abstract idea does not become nonabstract by limiting the invention to a particular field of use or technological environment, such as the Internet [or] a computer").

50 Bilski v. Kappos, 561 U.S. 593, 605, 95 USPQ2d 1001, 1007 (2010).

51 CyberSource v. Retail Decisions, 654 F.3d 1366, 1370, 99 USPQ2d 1690, 1694 (Fed. Cir. 2011).

52 Versata Development Group v. SAP America, 793 F.3d 1306, 1335, 115 USPQ2d 1681, 1702 (Fed. Cir. 2015).

53 CyberSource v. Retail Decisions, 654 F.3d 1366, 1370, 99 USPQ2d 1690 (Fed. Cir. 2011); Parker v. Flook, 437 U.S. 584, 590, 198 USPQ 193, 197 (1978).

54 Mayo Collaborative Servs. v. Prometheus Labs., Inc., 566 U.S. 66, 67, 101 USPQ2d 1961, 1964 (2010).

55 Mayo Collaborative Servs. v. Prometheus Labs., Inc., 566 U.S. 66, 67, 101 USPQ2d 1961, 1968 (2010).

56 DR Holdings, LLC v. Hotels.com, L.P., 773 F.3d 1245, 113 USPQ2d 1097 (Fed. Cir. 2014).
} 
conventional activity are not particularly high: receiving or transmitting data over a network, ${ }^{57}$ performing repetitive calculations, ${ }^{58}$ electronic recordkeeping, ${ }^{59}$ storing and retrieving information in memory, ${ }^{60}$ or a web browser's back and forward button functionality. ${ }^{61}$

Another patent that focused on a technical implementation was successful by providing a meaningful limitation beyond linking the use of the judicial exception to a particular technological environment. ${ }^{62}$ In this application, the claim was directed to the use of a specific equation (as an abstract idea a judicial exception) in an automated process for operating a rubber-moulding press. It was evaluated that the additional elements such as the steps of installing rubber in a press, closing the mould, constantly measuring the temperature in the mould and automatically opening the press at the proper time sufficiently limited the use of the judicial exception to the practical application of moulding rubber products. These cases are not precisely separable and overlap significantly. Therefore, in a patent claim assessment, they are applied cumulatively.

Other considerations to determine the integration of a judicial exception into a practical application exist, such as whether the claim effects a transformation or reduction of a particular article to a different state or thing; ${ }^{63}$ however, these are of little relevance for smart grid technologies.

\subsubsection{Applying Alice/Mayo to Smart Grid Technologies}

As described before, smart grid technologies rely heavily on AI, which is contained in or expressed by software application. Therefore, the invention as a whole would pass the first part of the test. Any patent claim of a smart grid device or process would be directed to an abstract idea.

Hence, the analysis in the second part focuses on the question whether the claims of such a smart grid patent application are reciting additional elements that amount to significantly more than the judicial exception of being directed to an abstract idea.

(a) As established before, according to the Alice/Mayo test, it is particularly harmful to patent eligibility if the software claim is merely amended by adding a generic computer or generic computer components, even if the generic computer is "specially programmed" or is a "particular machine". In the context of smart grid technologies, the elements of prediction of energy spikes in real-time based on a live

\footnotetext{
${ }^{57}$ TLI Communications LLC v. AV Auto. LLC, 823 F.3d 607, 610, 118 USPQ2d 1744, 1745 (Fed. Cir. 2016).

${ }^{58}$ Bancorp Services v. Sun Life, 687 F.3d 1266, 1278, 103 USPQ2d 1425, 1433 (Fed. Cir. 2012).

59 Alice Corp. Pty. Ltd. v. CLS Bank Int'l, 573 U.S. 208, 225, 110 USPQ2d 1984 (2014).

${ }^{60}$ Versata Dev. Group, Inc. v. SAP Am., Inc., 793 F.3d 1306, 1334, 115 USPQ2d 1681, 1701 (Fed. Cir. 2015).

${ }^{61}$ Internet Patent Corp. v. Active Network, Inc., 790 F.3d 1343, 1348, 115 USPQ2d 1414, 1418 (Fed. Cir. 2015).

${ }^{62}$ Diamond v. Diehr, 450 U.S. 175, 209 USPQ 1 (1981).

${ }^{63}$ Bilski v. Kappos, 561 U.S. 593, 605, 95 USPQ2d 1001, 1007 (2010); Gottschalk v. Benson, 409 U.S. 63, 70, 175 USPQ 673, 676 (1972).
} 
analysis of data and the process of energy distribution cannot be achieved with existing energy grid technology. New so-called smart meters have to be installed and connected with energy distribution systems. Those systems also have to be upgraded to allow for dynamic adjustments. Therefore, a smart grid is usually more than simply running specific software on a "generic computer", because its function heavily relies on specific hardware as well.

(b) Consequently, it can be said that the AI running a smart grid plays a significant part in permitting the claimed method to be performed, rather than functioning solely as an obvious mechanism for permitting a solution to be achieved more quickly. Dynamic energy distribution and energy consumption prediction as well as the identification of attack patterns are currently not possible without AI. This is simply because the required amount of data has not been collected and can only be meaningfully processed by the computing capabilities of a smart grid. It is an entirely new approach instead of merely executing an existing approach of energy grid management faster or more efficiently.

(c) Therefore, it is very unlikely that a complex smart grid initiative is determined to be a case where the use of a machine only contributes nominally or insignificantly to the execution of the claimed method. The very execution of the method relies on the implementation of the machines to collect the very data that allow the AI to be trained. It is important to be aware of the fact that an AI within a smart grid is not simply a static computer program but a dynamic process of an ever-evolving algorithm. Using smart meters and more capable energy access points is an essential part of making the smart grid possible in the first place.

(d) Finally, it has to be determined whether the AI might be categorized as a well-understood, routine, conventional activity previously known to the industry. Since this has been rejected in a case where the approach used differed from the conventional operation, it is arguably equally easy to reject this notion in the instant case.

In comparison, the Alice/Mayo test is seemingly stricter than the EU approach but does not ultimately oppose smart grid patent applications. However, to satisfy the USPTO standard, the technical necessity and standard of the smart meters has to be emphasized much more clearly, as well as the novelty of the software approach in distinction to the industry standard.

\subsection{China's Approach to AI-Related Inventions}

Having the second largest number of patent filings concerning AI-related inventions in the world, ${ }^{64}$ China perceives itself to be the world's leader in AI. ${ }^{65}$ However, the National Intellectual Property Administration of China (CNIPA) has only recently begun to accumulate experience in the examination of AI-related inventions. To

\footnotetext{
${ }^{64}$ World Intellectual Property Organization, Technology Trends 2019 - Artificial Intelligence (WIPO 2019), pp. 85-87.

65 Liu and Liu, "Patent Examination on Artificial Intelligence-related Inventions: An Overview of China", p. 2 et seq.
} 
adjust its patent regime to AI-related inventions, China has also issued new examination guidelines.

The current Chinese patent law regime consists of three tiers. The Chinese Patent Code and its interpretation made by the Supreme People's Court, regulations issued by the State Council, such as Rules for the Implementation of the Patent Law (Implementation Rules) and operation documents enacted by the CNIPA. The most representative among these legal sources are the Guidelines for Patent Examination. These guidelines define some of the broader terms within the Patent Code and instruct examiners on how to assess certain more challenging inventions. Patent examiners are bound by the guidelines, which therefore have a significant role in the practice of patent examination. Similar to the EU guidelines, the patentability of AIrelated inventions is subject to recent provisions. Patent eligibility of such inventions was very vague until the revised guidelines took effect on 1 April $2017 .{ }^{66}$

\subsubsection{Basics of the Chinese Patent Code}

Article 2.2 of the Chinese Patent Code defines key requirements for patentability. An invention is patentable if it contains a technical solution, which, by following natural rules, exploits technical means to solve technical problems. A technical solution is an aggregation of technical means applying the laws of nature to solve a technical problem. Usually, technical means are embodied as technical features. ${ }^{67}$ Article 25 of the Chinese Patent Code excludes the patentability of six kinds of subject matter, one of which are rules and methods for mental activities. ${ }^{68}$ Following this article, the Guidelines for Patent Examination further clarify that a claim concerning only rules and methods for mental activities is not patentable. ${ }^{69}$

Similar to the EU and US approaches to patent law, algorithms are considered rules and methods that merely contain algorithms or mathematical rules. Therefore, all jurisdictions agree in this case that such claims do not contain any technical solution, because neither technical methods nor technical features are embodied therein. Without satisfying the key requirement such a proposed invention lacks patentability. In practice, Arts. 2.2 and 25 of the Chinese Patent Code are closely related, and patent examiners frequently refer to both of them when examining applications relating to computer programs. ${ }^{70}$ Naturally, AI-related inventions are no exception. For example, supervised learning and semi-supervised learning are typical learning methods for machine learning, a sub-field of AI that is concerned with the automated detection of meaningful patterns in data and using the patterns for specific tasks. ${ }^{71}$ But an application claiming these learning methods is nonpatentable if such methods merely relate to numerical calculation and do not improve on the performance of hardware. As with the EU guidelines, it is necessary

\footnotetext{
${ }^{66}$ CNIPA Guidelines for Patent Examination 2017, Art. 4.2(2), Chapter 1, Part 2.

67 CNIPA Guidelines 2014 for Patent Examination, Art. 2, Chapter 1, Part 2.

68 Patent Law of China 2008, Art. 25.

69 CNIPA Guidelines 2014 for Patent Examination, Art. 4.2, Chapter 1, Part 2.

${ }^{70} \mathrm{Li}$ and Liu (2016), pp. 102, 113; He (2020), p. 6; USPTO (2019), Section 2106.5(a).

71 So (2018), pp. 121-128.
} 
to have a specific connection to the technical implementation of the software. As an example, an AI-related application was rejected by the CNIPA based on lack of patentability. The Patent Reexamination Board (PRB) affirmed the CNIPA's decision by holding that what has been claimed in the application, in essence, is a function to classify set elements via mathematical algorithm on a sample set. ${ }^{72}$

It seems that rejecting the patentability of abstract mathematical models or logical systems is an internationally common practice. ${ }^{73}$ This is intended to avoid monopolizing these concepts. Monopolization could impede innovation rather than promoting it. $^{74}$

\subsubsection{Recent Update on Examination Guidelines}

The effect of Art. 25 of the Chinese Patent Code on the patentability of AI-related inventions, as well as the examination practice, has resulted in refusing most AIrelated patent applications. However, China is under the impression that granting legal certainty and stronger patent protection to AI-related inventions will "undoubtedly" lead to more investment. ${ }^{75}$ Therefore, to strengthen IP protection for creations in the most recent IT research areas ${ }^{76}$ and to develop those industries the policies were changed. ${ }^{77}$ Consequently, the CNIPA amended their guidelines, in particular reconsidering those provisions that lead examiners to dismiss AI-related applications.

This involved two significant changes: First, it was considered that business methods improved by AI could increase the efficiency of business activities. ${ }^{78} \mathrm{~A}$ theoretical application for this might be a smart grid initiative. To address the issue a new provision was added to the guidelines which provides that if a claim related to a business model contains both business methods and technical features, it is eligible for patentability. ${ }^{79}$ Even though this provision does not specially address

\footnotetext{
72 No. 120841 Decision of PRB (29 March 2017).

73 Additional to the already mentioned aspects, this is also the same case in Japan. The Examination Guidelines of the Japanese Patent Office (JPO) enumerate the subject matters in which the laws of nature are not utilized, and a mathematical formula is one of those not eligible for a patent (Examination Guidelines for Patent and Utility Model in Japan 2015, Section 2.1.4, Chapter 1, Part III). Therefore, an invention relating to computer programs, to qualify as a patentable invention, needs to contain technical features in addition to rules and methods for mental activities. More specifically, patentable inventions relating to computer programs generally solve certain problems via, either in whole or in part, running computer programs, to control or process the external or internal objects of a computer. Technical effects achieved in this way shall be in conformity with natural rules as well as those rules governing computers.

74 Alice Corp v. CLS Bank Int'l, 134 S. Ct. 2354, 110 USPQ2d 1980; Mayo Collaborative Servs. v. Prometheus Labs., Inc, 566 U.S. 66, 71, 101 USPQ2d 1961, 1965 (2012).

75 State Council's opinions on Accelerating the Construction of Great Power via Intellectual Property under the New Circumstances (2015), Section 11, Part 3.

76 Such as the internet, e-commerce and big data.

77 State Council's opinions on Accelerating the Construction of Great Power via Intellectual Property under the New Circumstances (2015), Section 11, Part 3.

78 CNIPA Guidelines for Patent Examination 2017, Art. 4.2(2), Chapter 1, Part 2.

79 CNIPA Guidelines for Patent Examination 2017, Art. 4.2(2), Chapter 1, Part 2.
} 
AI-related inventions, it can also be applied to a business model invention employing AI, such as a smart grid initiative.

As a recent example, a patent application named "A Method for Targeted Advertising Based on the Big Data regarding User Habit in a Region" claimed an intelligent system consisting of several data processing modules. The system, via invoking those modules, can remind merchants to stock up on products that customers will buy in a short period and also notify customers to buy those products before they run out. Efficiency of transactions was said to be raised significantly by this business method through the collection and analysis of data such as target customer and merchant data. ${ }^{80}$ The CNIPA found this patent application patentable on the basis that even if the claims thereof contained rules and methods, they have achieved technical effects. ${ }^{81}$ It seems likely that such a line of argument will also be applicable to smart grid designs involving AI-generated algorithms or AI systems.

The second change follows the distinction between AI-implemented inventions and pure algorithms themselves. This allows the claims of the former to be a combination of hardware and algorithms of a computer program. Previously, algorithms of a computer program fell into the scope of rules and methods for mental activities and were not eligible for patent protection. The prior version of the guidelines did not differentiate between computer-program-implemented inventions and the algorithm itself, ${ }^{82}$ which may have been a reason for examiners to misunderstand that inventions relating to computer programs are unpatentable in general. Therefore, it was clarified that an algorithm itself is unpatentable but inventions with implemented algorithms might be patentable. ${ }^{83}$ It is expected that examiners are led by this approach towards granting approval in more cases, since AI-related inventions are usually part of an implementation.

\subsubsection{Example of China's New Patentability Approach}

As mentioned above, one typical application of AI is imitating the ways humans perceive and categorize information. One of the first cases in China revolved around image recognition and processing. ${ }^{84}$ AI-trained algorithms could be used to enhance the display effect of medical images supporting auxiliary diagnosis. The AI trains the algorithms to detect patterns of data in order to automate complex tasks or make predictions. ${ }^{85}$ In this case, a patent application claimed a method to enhance the display effect of medical images by using correctional and multiscale retinex algorithms. The claims of the patent application consisted of four elements:

\footnotetext{
${ }^{80}$ CNIPA Patent Application No. 201811482899.X.

81 Liu (2019), pp. 4, 21.

82 CNIPA Guidelines 2014, Sections 1 and 2, Chapter 9, Part 2.

83 Surden (2014), pp. 87, 89-91.

84 Singh, “AI capabilities in Image Recognition” (Towards Data Science, 12 November 2018).

85 Surden (2014), pp. 87, 90.
} 
First, obtaining image sequences in a nidus ${ }^{86}$ or of a target part. Then enhancing those image sequences and combining the enhanced image sequences. Ultimately, those combined image sequences are treated in such a way as to make them more easily readable, further increasing the potential for accurate diagnoses. ${ }^{87}$ The AItrained algorithms are primarily used in the second step by converting the grey value of the image sequences to floating-point type. The use of the trained functions and formulas to enhance the grey level image of all image sequences and obtain images with enhanced edges was the core task of the algorithms. The CNIPA held the opinion that those technical solutions claimed in the application enhanced the display effect of the image edge and thus increased the visibility of a nidus or target part. ${ }^{88}$ Since it is helpful for doctors to distinguish organs with identical or similar shape and to improve the accuracy rate of treatment, the claims have technical effects and are able to satisfy the requirements set in Art. 2.2 of the Chinese Patent Code. Hence, the patent was granted by the CNIPA. Similarly, another patent application concerned with convolutional neural networks was approved by the CNIPA. It was argued that such an application of neural networks could increase the accuracy rate of detecting hand gestures and thereby reduce the computational burden in the process of training. ${ }^{89}$

It is worth noting that the most significant argument for their patentability is whether their claims could achieve technical effects. This is almost identical to the requirements given by the EPO and the USPTO. However, the challenge of drawing a line between AI applications with technical effects and those without remains apparent in all jurisdictions.

However, there is one decisive difference in the foregoing analysis. The practice of the CNIPA allows for a much looser connection of algorithm and technical effect. In both the aforementioned patents approved by the CNIPA, the result of the algorithm was mainly due to its effect on the computational speed and accuracy. Such optimizations are not sufficient under EU patent law, which requires a more direct technical effect. It is sometimes even argued in Chinese patent law that further removed goals from the technical effect, like a target advertising method and even improvement or optimization of user experience, can be deemed a technical effect. It is worth mentioning that, as believed by examiners, such experience should be an objective effect arising from a combined action of natural rules and humans' biological attributes, and should not be judged solely based on users' subjective feeling. ${ }^{90}$

\footnotetext{
86 The centre of a bladder stone.

87 CNIPA Patent Application No. 201710007475.7.

88 CNIPA Patent Application No. 201610707579.4.

89 Sumit, "A Comprehensive Guide to Convolutional Neural Networks - the ELI5 way (Towards Data Science, 16 December 2018), 3. Liu (2019), pp. 4, 21.

90 Liu and Liu, "Patent Examination on Artificial Intelligence-related Inventions: An Overview of China", p. 24.
} 


\subsubsection{AI as the Inventor of Software Solutions}

Another issue raised by smart grid initiatives is the concept of "inventor" in patent law. In case the AI develops an algorithm that is ultimately the main part of a patentable invention, it might be difficult to identify the inventor of the invention as a whole. Generally, the inventor specified within a patent application must be a natural person. ${ }^{91}$ In order to be considered an "inventor" within the meaning of patent law, this person must actually have implemented part of the inventive concept. $^{92}$

Conceptually, this limitation arises from the fact that an invention is the solution of a technical problem; the ability to identify problems is so far limited to humans because an AI is unable to do so without prior definition of the "problems" by a human developer. The current state of computer science does not allow for the development of so-called "strong AIs". 93

For the current stage of AI development, it is helpful to make the following distinction: A mere application of a machine learning process to solve a specific data set for a specific problem can, under the aforementioned conditions, be interpreted as a pure auxiliary algorithm that does not constitute a patentable invention. This is because the AI system itself does not become part of the invention since only the target algorithm is implemented in a technical way. If the target algorithm, for example as in the described model of genetic breeding, was developed without any human intervention outside of the creation of the environment, patentability - regardless of the question of whether the algorithm is patentable - might be excluded because no human inventor exists. This can be the result of the application of a target algorithm by a human developer to a technical problem in a technical environment in order to achieve patentability in the first place. Given the complexity of solutions in the context of a comprehensive smart grid, it is practically impossible that the algorithm can only be classified as a pure auxiliary algorithm. Overall, however, there is currently a lack of clarity regarding the ownership of artificial inventions.

Most recently, the EPO had to deal with a patent application regarding Art. 81 EPC, since the applicant named the AI "DABUS" as inventor. This application was considered invalid. The EPC indirectly confirmed that AI has no legal personality and is therefore unable to obtain rights. The "trainer", i.e. developer, of the AI might be the inventor; however, when an AI becomes more and more complex, it becomes less likely that the results of the AI are still attributed to the original work of the programmer. ${ }^{94}$ The applicant however still insists on naming the AI as inventor, even after the applications were dismissed. In September 2020,

\footnotetext{
91 Re Chinese patent law: He Jun, Senior Judge, Intellectual Property Court of the Supreme People's Court of the People's Republic of China, WIPO Conversation on Intellectual Property and Artificial Intelligence, Issue 2: Patents: Inventorship and Ownership, 2020, 1. Re US patent law: USPTO decision re the application 16/524,350 from 22 April 2020.

92 Bahke (1985), p. 596 et seq.

93 Fjelland (2020), p. 42 et seq.

94 Pesch (2020), p. 84.
} 
after escalating the issue, the applicant lost the appeal. ${ }^{95}$ Similar decisions have been made by the USPTO ${ }^{96}$ and the United Kingdom Intellectual Property Office (UKIPO). ${ }^{97}$

\subsection{The Different Perception of Patent Law in China}

As described in the beginning, the new patent guidelines of the CNIPA are primarily influenced by the political agenda of incentivizing innovation and technology. There is some discussion about the necessity of extending the scope of IP protection to cover AI-related creations. ${ }^{98}$ In addition, US and European patent law has been the subject of numerous discussions on whether patents actually incentivize or restrict innovation. ${ }^{99}$ While those debates also consider the patent as an incentive for the inventor, there are other motives as well, such as the concept of the patent as a personal reward. However, the clear premise of Chinese patent law is to be a motor of invention. This political function is connected to the general perception of patent law in China. To understand the political motivation, it is necessary to identify how the perception of intellectual property is different from other patent law jurisdictions.

For example, in the US case Alfred Bell $v$ Catalda Fine Arts, ${ }^{100}$ the Second Circuit Court has drawn an analogy between copyright and patent. ${ }^{101}$ According to Chinese scholars, however, this analogy is flawed because patent rights are defined by a different set of rules and are said to be "focusing on the 'inventiveness' of the discovery". That is due to the sentiment that Chinese patent law is usually perceived from a very utilitarian perspective. Therefore, even if a scientific discovery was the result of an accident, granting patent rights to the first discoverer from a utilitarian perspective is beneficial to society. Under such a utilitarian perspective, granting copyright to unintentional creations is not as easily justifiable because copyright is not regarded as such a utilitarian concept.

To understand the specific Chinese perception of patent law, it is necessary to keep in mind that the very concept of intellectual property is fairly new to Chinese legal culture. Even though the Chinese government invested substantial resources in promoting the new patent system, only a very rudimentary idea of patents exists among the Chinese populace. Most Chinese lack a basic understanding of patent law. ${ }^{102}$ Even among the better-educated population, a significant portion of people

\footnotetext{
95 England and Wales High Court.

${ }^{96}$ See supra note 91.

${ }^{97}$ UKIPO decision re the patents GB1816909.4 and GB181861.0, issued 4 December 2019.

98 Perry and Margoni (2010), p. 10 et seq.; Shoyama (2005), p. 136; Legner, ZUM 2019, 811 et seq.

99 With further references: Jänich (2002), p. 255; Barnes (2010), p. 97; Leistner and Hansen (2008), pp. 479, 484.

100 Alfred Bell \& Co. Ltd. v. Catalda Fine Arts, Inc. et al, 191 F.2d 99 (2d Cir. 1951).

${ }^{101}$ CNIPA, Explanation on the Draft Amendment to Chapter 9, Part 2 of the Guidelines for Patent Examination (2019), 1-2.

102 According to two studies, most people have heard of patents but especially people in rural regions acknowledge that they do not understand them well: Hua Liu (2006), pp. 103, 105, and Wang (2016), p. 175 .
} 
in China think that patents either assure a certain quality of a product ${ }^{103}$ or directly refer to advanced technologies. ${ }^{104}$ In addition, college students were likewise unable to understand the different concepts of intellectual property rights or even point out the differences between them. ${ }^{105}$ The former CNIPA commissioner identified the lack of understanding of IP as a "fundamental shortcoming" of IP research and significance in China. ${ }^{106}$ While such a limited understanding of patent law is not unique to the Chinese public, the effect in the Western world with a more longstanding tradition of intellectual property going back centuries is considered less significant. $^{107}$

Additional efforts by the government to further the acceptance and understanding of patents were made. Exactly these efforts shaped the legal culture in patent law somewhat differently compared to US and European patent law. For example, a policy was created that allowed students to gain extra advantages in entrance examinations for universities if they had successfully filed for a patent. ${ }^{108}$ Additionally, successful patent applications can be taken into consideration by administrative officials in disciplinary measures to reduce demerit punishments or eliminate a disadvantageous record of disciplinary proceedings. ${ }^{109}$ Furthermore, even prisoners can benefit from being creative and innovative. A prison sentence can be reduced by a successfully obtained patent. ${ }^{110}$

It becomes obvious that the functions of patents in China are more far-reaching than in other jurisdictions. They extend beyond the economic value of the exclusionary right and have value in other - arguably distant - areas of law as well. These additional values shape the perception of patents accordingly. Even if the thought of a patent as an incentive for inventive undertakings exists in Western legal culture, there are no such effects of patents that extend into completely different areas of law. It might even be argued that the understanding of a patent by the Chinese public is distorted by these measures, because it leads to the conception that

\footnotetext{
$\overline{103}$ Meng and Meng (2011), pp. 144, 146; Liu and Ying (2006), pp. 103, 110.

104 Tan (2017), pp. 144, 149; Tännsjö (2007), pp. 330, 338.

105 He (2011), p. 42; Peng (2018), p. 62.

106 Peng (2018), pp. 62, 30; Fu (2014), p. 156; Liu and Fan (2007), pp. 1582, 1590; Meng and Meng (2011), p. 96.

107 Mandel, 66 Fla. L. Rev. 261 (2014), who criticizes that the public psychology of intellectual property has barely been explored.

108 Peng (2018), pp. 62, 30; Zhang and Xiado, “Zhanli Shizi Tiaojian" [Substantial Requirements for Patent], in: Chengsi Zheng (ed.), Law Press (2002); Zheng, "Gongxu Liangsu Yuanze zai Zhongguo Jindai Minfa Zhuanxing zhong de Jiazhi" [The Value of the Principle of Public Order and Good Morals in the Transformation of the Civil Law of Modern China], 11 Faxue [Law Science] 87, 98 (2017).

109 Peng (2018), p. 62; Wu, "Zhongguo Zhuanli Fa de Fazhan Daolu: Xiandaihua, Guojiahua yu Zhanlüenhua - Zai Zhongguo Zhuanli Fa Banbu 30 Zhounian Zuotanhui Shang de Fayan" [The Development Paths of the Chinese Patent Law: Modernizing, Internationalizing, Strategizing - An Address in Colloquia "the Issuing of the Chinese Patent Law" 30th Anniversary], 3 Zhishi Chanquan [Intellectual Property Journal] 10, 15 (2014).

110 Article 78(1) of the Criminal Law of the PRC and Art. 29(3) of Prison Law of the PRC; also, Qia and Molloy; Allison and Kirk, 16 BMC Medical Ethics 85 (2015), 15 et seq.; Tian, "Shengming Xingshi Zhishi Chanquan ji Guojia Zhengce" [Intellectual Property Right of Life Form and National Policies], Zhongguo Nongye Chubanshe [China Agriculture Press] (2003).
} 
a patent is inherently positive. In the eyes of the public, only such a high standard of a patent would lead to such significant benefits granted by the state government. A patent is perceived as a guarantee of quality from the central government. ${ }^{111}$ Consequently, this influences the question whether a patent is truly neutral due to its exclusionary nature. It is likely that the vigorous promotion efforts by the Chinese government transformed the grant of a patent into a government reward in the form of a technical authority or advanced technology.

Ultimately, a patent is understood as a government endorsement of a high-tech product. ${ }^{112}$ With all these factors, the exotic nature of patent law in China, the very recent development and the endorsement effect, combined, it is understandable that for the Chinese public, a patent is a "thing with a sense of mystery ... even a sense of the sacred". 113

This also helps to explain the effort by the Chinese government to grant more AIrelated patents, since a patent is regarded as an inherently positive asset. However, that might not be case - given the exclusionary nature of a patent right and economic considerations of patents, especially in the context of AI and algorithms. $^{114}$

\subsection{Copyright Protection of Machine Learning}

Besides patent law, scholars have been looking into protecting AI-related creations through other areas of law. Since this article focuses mainly on patent law, the following analysis will only give a short overview and use German copyright law and Chinese copyright law as examples. Chinese copyright law is of particular interest because it is a rather new legal development and has only recently gained importance on a global level. On the other hand, German copyright law has a long history and its inherent connection to a personal right of the author is unique among all relevant copyright jurisdictions. Therefore, a comparison between these jurisdictions allows for insights into how legal culture influences the development of law.

\subsubsection{Copyright Protection Under German Law}

An algorithm might be protected under German law, for example, according to Sec. 69a III UrhG (German Copyright Act). ${ }^{115}$ However, under German law this is only possible if it is the result of a human creative process. In this respect, the problem is comparable to the inventive step in patent law. In copyright law, too,

\footnotetext{
111 Meng and Meng (2011), pp. 144, 146; also, Peng (2018), p. 63.

112 Yin, "Zhongguo Zhuanlifa Xiangjie" [Introduction to the Patent Law of China], Zhishi Chanquan Chubanshe [Intellectual Property Press] (2011); Peng (2018), p. 63.

113 Peng (2018), p. 63.

114 Dornis (2019), p. 1259, arguing that the protection might not be economically necessary. Others say that a paradigm change is necessary: Lederer (2019), p. 152, because the development of the core AI that ultimately constructs the valuable target algorithm is currently not protected and therefore not incentivized.

115 Section 69a UrhG provides protection for computer programs.
} 
autonomously acting machines can be used as aids and contain certain random elements. ${ }^{116}$ However, no protection is granted if the human activity is purely a background activity in the process of creation. ${ }^{117}$

Protection as a database work in accordance with Sec. 4 II UrhG requires a collection of creations, data or other independent elements that are systematically or methodically arranged and individually accessible using electronic or other means. ${ }^{118}$ The selection or arrangement of the elements would also have to represent a personal intellectual creation, so that the target algorithm of a machine learning process cannot be protected as a database. Protection of the machine learning environment, which can still be considered as a personal intellectual creation, however, is not protectable by the database work provision because the data sets fed into the system usually have no independent use and are therefore not "independent" of the other contents of the database according to the provision. ${ }^{119}$

In the context of the smart grid, all possible consumer data and supplier data are necessarily recorded, so that at least a selection of the data is still available to the developer, which is sufficient for personal creation, but not as a classification as a database within the meaning of Sec. 4 II UrhG.

Another option in this context - different from German copyright law but comparable as a sui-generis property right - is the database right according to Sec. 87a UrhG. This section is based on EU Directive 96/9/EC and grants rights to certain computer records. The main difference to the aforementioned copyright protection of Sec. 4 II UrhG lies in the fact that the database right of Sec. 87a UrhG does not require personal intellectual creation, thereby providing more protection to the substantial investments necessary to establish a database. However, the elements within the database still have to be independent and are systematically or methodically arranged. While it is conceivable that the database of an AI is arranged correspondingly, the elements are part of a greater network or arrangement and exclusively make sense in that context. Again, they usually cannot be considered independent.

A database of consumer and supplier data may enjoy protection according to Sec. 87a UrhG as a database right but it falls short of offering protection to the actual network data nodes that make up the background for developing the AI and the target algorithm. Also, an evaluation of Directive 96/9/EC by the European Commission found that the economic impact of database rights fell behind the expected function as a significant incentive. ${ }^{120}$

\subsubsection{Chinese Copyright Regulations}

Like almost all other copyright jurisdictions, the Chinese legal approach does not have the strong connection of copyright and personal right. According to Art. 2 of

\footnotetext{
116 Bullinger, in: Wandtke and Bullinger, "UrhG", § 2 re 16, 17.

117 With further research: Ehringer and Stiemerling (2018), p. 764 et seq.

118 Ehringer and Stiemerling (2018), p. 764.

119 Ehringer and Stiemerling (2018), p. 765 et seq.

120 EU Commission, Evaluation of Directive 96/9/EC on the legal protection of databases, 5.2.2. (2018).
} 
the Regulations for the Implementation of the Copyright Law (RICL), the term "works" as referred to in the Copyright Law of the People's Republic of China (CLC) means intellectual creations with originality in the literary, artistic or scientific domain, insofar as they can be reproduced in a tangible form. Originality is the most relevant criterion required for a creation to be considered as a "work" in China. Historically, the CLC failed to mention the "originality" requirement to avoid confusion with patent law concepts such as "novelty" or "inventive step". 121 After the concept of "originality" was introduced, the inconsistent interpretation of the originality requirement by Chinese courts became a new challenge. ${ }^{122}$ Article 15 of the 2002 Interpretation of the Supreme People's Court (SPC) states that if a work was created by different authors on the basis of the same topic, the authors shall enjoy independent copyright if the expression of the work is completed independently and is creative. ${ }^{123}$ In jurisprudence the requirement of creativity could be very low, ${ }^{124}$ making it resemble the US standard. Without its own originality approach, the most challenging part of addressing AI-generated content in China is the standard in determining originality. One opinion in the legal literature argues that when assessing the originality of a work, a court should only focus on the result, not the creative process. ${ }^{125}$ Consequently, following this line of argument AIgenerated contents fulfil the requirement of originality. If at least some level of creativity is inherent in the result of the work, it is then considered original. ${ }^{126}$ Opposed to that is the argument that a subjective standard is necessary, in which the creative process is decisive for determining originality. ${ }^{127}$ In a 2006 case, the Henan Higher People's Court ruled that the silhouette of a stone tablet was not original, as "there is not enough evidence to prove that the tablet maker has conceived the silhouette and used his skill to shape the tablet in a certain way". ${ }^{28}$ In the Film v Baidu case - the first AI and copyright case in China concerning a data report generated by an AI program - the Beijing Internet Court ${ }^{129}$ also investigated the AI generative process of the report when determining originality. It was stated that "an author is a human being who intends to produce one or more mental effects in an audience by an external manifestation of behavior". ${ }^{130}$ Both these cases indicate that the courts follow the subjective standard.

\footnotetext{
121 CNIPA Patent Application No. 201610707579.4.

122 IThinkTank (2019).

123 Cohen and Lemley (2001), pp. 37-40.

124 CNIPA Patent Application No. CN201620623756.6.

125 CNIPA Patent Re-examination Board of the CNIPA, Research Report on the Protection of Innovations in the New Form Industry (2019), 18.

126 CNIPA Patent Application No. CN201620523181.0.

127 CNIPA Patent Application No. CN201710743121.9.

128 CNIPA Guidelines 2017, Art. 1, Chapter 9, Part 2.

129 Internet courts are courts of special jurisdiction that hear internet-related cases like web-based copyright infringement.

130 CNIPA Patent Re-examination Board of the CNIPA, "Research Report on the Protection of Innovations in the New Form Industry" (2019), p. 21.
} 
In addition, most Chinese scholars argue that an analysis based solely on the product to determine originality is insufficient. Without looking at the creation process as well, it may not be possible to distinguish between a work of nature and the work of humans. ${ }^{131}$ This raises the practical problem that AI-generated content might be sophisticated enough to mislead the public about its origin. Even if the creative process is taken into account, it is very difficult to assess the process without sufficient documentation. Considering the fact that algorithms are able to create much faster than humans, it is necessary that the creative process of AIgenerated content is sufficiently documented to prove the originality of the end result.

\subsection{Approaches for More Certainty of AI Creations}

In order to establish clarity for AI-generated content, scholars from different jurisdictions have proposed that the ownership of IP rights should be extended to include computing entities. ${ }^{132}$ Unlike the copyright laws of traditional civil law countries such as Germany - where such an extension would distort the very core of copyright law - the CLC is actually a hybrid of civil law and common law traditions and principles. The CLC not only recognizes moral rights and clearly provides that the actual author is the initial copyright owner, ${ }^{133}$ but also allows legal persons to be considered as authors ${ }^{134}$ and considers the producer of a cinematographic work as the copyright owner. ${ }^{135}$ For some scholars it is only the next logical step that "computers/machines" can also be deemed authors in the CLC. ${ }^{136}$ Putting machines in the position of an author might help in distinguishing human and non-human authors, thereby preventing the former from free-riding on the latter. The same line of argument can also be applied to the term of "inventor" in patent law.

However, especially in the context of German and European copyright and patent law, this idea has been strongly rejected. The concept of German copyright requires human creativity, not randomness. AI is supposedly soulless and therefore unable to access the concept and content of original artworks, such as a painting. ${ }^{137}$ This is based on the functionality of algorithms and their inherent system of "if - else" operators which do not resemble the inspiration of a natural person sufficiently. ${ }^{138}$ Human creativity is based on sensibility and experience that define the human

\footnotetext{
131 Liu and Liu, "Patent Examination on Artificial Intelligence-related Inventions: An Overview of China", p. 9.

132 He, Asia Pacific Law Review 2019, p. 226.

133 Copyright Law of the People's Republic of China, 2010, Arts. 16 and 17.

134 Copyright Law of the People's Republic of China, 2010, Art. 2.

135 Copyright Law of the People's Republic of China, 2010, Art. 15.

136 Brown (2018), pp. 1, 2.

137 Ory and Sorge, NJW 2019, 712.

138 Ory and Sorge, NJW 2019, 713 - describing the process to be similar to sampling because it is more of an extraction without an individual component and no inner distance, which is required under German law to be considered an independent work.
} 
personality in general. ${ }^{139}$ Therefore, the difference between human intelligence and AI might not be defined by the difference in cognitive but rather core emotional abilities. ${ }^{140}$ Any meta levels of an algorithm that would constitute something akin to personality have to be defined by a human programmer. ${ }^{141}$ It becomes apparent that this discussion quickly moves from considerations of law and computer engineering into areas of psychology and philosophy. ${ }^{142}$ The level of incorporation of AI in the creation process is also regarded as essential. It is almost universally agreed that copyright and patent law do not cover discoveries as well - you cannot display something that you find as a creation that you did not create. ${ }^{143}$

\section{Economic Considerations and Compulsory Licensing as an Alternative Approach}

The analysis has shown that the Chinese approach to AI-related inventions is influenced by the Chinese perception of patent law as an economically and societally beneficial right. In addition, scholars from other jurisdictions have argued to extend the protection for AI to set more incentives for potential investors.

However, it might be necessary to look at patent law through a more economic and pragmatic lens. The development of AI has skyrocketed in recent years even without any explicit protection by patent law. However, most AI systems require huge amounts of data, which represent a market entry barrier, especially in areas with such a complex and enormous scale as smart grid initiatives. ${ }^{144}$ Training data is usually a trade secret and therefore not patentable because it is not provided in the patent application. ${ }^{145}$ Yet, access to certain areas of the market could be considered as subject matter for a compulsory licence. ${ }^{146}$ If one follows the basic idea of intellectual property law to the extent that this is intended to create a balance between exclusion rights and availability, a conflict of interest may be identified at this point. It makes sense to change perspective: Instead of thinking about further exclusion rights for AI-related creations, a more valuable approach could be in the opposite direction of application, by creating more availabilities for the general public. In the current discussion about AI-specific adaptations and the granting of rights, this aspect has more of a shadowy existence, although it is precisely the concept of compulsory licences ${ }^{147}$ and standard essential patents ${ }^{148}$ that shows that the availability of rights for the general public and not creating another right of

\footnotetext{
139 Lauber-Rönsberg (2019), p. 251.

${ }^{140}$ Lauber-Rönsberg (2019), p. 252.

141 Lauber-Rönsberg (2019), p. 244.

142 Dornis (2019), p. 1252, describing artificial creativity in a psychological context.

143 Lauber-Rönsberg (2019), pp. 244, 252; Ory and Sorge, NJW 2019, 712.

${ }^{144}$ Re search engines: Telang, Rajan and Mukhopadhyay (2014), p. 137 et seq.

145 Lederer (2019), p. 153.

146 Wolf, in: "MüKo, competition law", Art. 102 TFEU, re 1227 et seq.

147 Wernicke, in: "The Law of the European Union", Art. 345 TFEU, re 20, 22 et seq.

148 Dornis (2019), p. 690.
} 
exclusion is also a legitimate goal of intellectual property law. Based on this basic idea, considerations about transferability and practicability can be made. Given the complexity of this subject, it is unrealistic to provide a comprehensive analysis within this paper, but some general ideas may already be considered.

Public interest functions as a restriction mechanism in order not to shift the balance of interests of compulsory licences unilaterally in favour of the licensees. ${ }^{149}$ The existing principles of public interest in patent law could be ideally used for this purpose, because they have been developed in a very technical environment. ${ }^{150} \mathrm{~A}$ smart grid system that ensures the use of sustainable energy can very well be considered a public interest. Given the necessity of drastically reducing the production of carbon dioxide, it is possible to call the requirement for more and faster integration of sustainable energy a response to a global crisis. ${ }^{151}$

This would make it possible to use the already mentioned concept of market entry barriers in order to dissolve monopoly positions that do not work in the general interest. In patent law, the relevant case law usually involves pharmaceutical inventions to combat public health emergencies. ${ }^{152}$ This shows that this concept is certainly not limited to smart grid initiatives, but the novel factor is the nature of the licensed object. With the explanations given above, in certain cases the object of the licence might be a patent for implemented software that provides control of the technical process. In cases where AI is used to create an algorithm that is implemented into the smart grid although the AI itself is not, the concept of compulsory licences has to be adapted.

Naturally, there are some challenges with this idea; primarily, the vague specification of the licensed object of AI. Without a definition, the concept of the compulsory licence loses its practical effect. It might be possible to use data sets or data conditions as the licensed object, although the object would change dramatically depending on the specific type of AI system used. An additional benefit of using data, however, is the fact that this prevents existing rights, such as database rights or copyrights to the source code, from being interfered with.

There are approaches to potentially define a subject for a compulsory licence. For example, AI creating an algorithm to run a smart grid uses an immense amount of data that was collected by the smart devices of the smart grid. Allowing other smart grid initiatives to obtain the data that are used by the AI by way of a compulsory licence accelerates the process of training a new AI to create an algorithm to control a new grid. Another way would be to license the AI or certain parts of the AI such as the data of the nodes of a neural network or the parameters of a Genetic Breeding Algorithm. By providing the nodes or the parameters, the new AI environment can be adjusted to the specifics of individual power grids. The challenge of this

\footnotetext{
149 Mes, "Patent Act", § 24, re 14 et seq.

150 Osterrieth, "Patentrecht", § 24, re 632 et seq.

151 With on overview of the academic scholarship on the topic of essential facilities and IP rights: Leddy and Marquardt (2003), p. 847 et seq.; Turney (2005), p. 179 et seq.

152 Re German patents: BPatG, PMZ 1974, 319; BPatGE 32, 184, GRUR 1994, 98; BGH, GRUR 1996, 190 - Interferon gamma; BGH, GRUR 2017, 1017, Mitt. 2017, 403 - Raltegeravir; BPatG, GRUR 2017, 373, PMZ 2017, 189 (Ls.) - Isentress; GRUR 1993, 308, 312; recently: BGH, PharmR 2017, 441.
} 
approach lies in the nature of the AI and its data. Since the AI or its algorithms are likely to be outside of legal protection because they are not human creations, no legal object in the form of a right exists which is usually the object of a licence. Therefore, it would be necessary to establish a new form of right regarding the data or the AI, which in turn can be the subject of compulsory licences. It seems that this might be counter-intuitive, but from a practicability stand-point it actually makes things easier. The licensor who will become the subject of the compulsory licence is simply the person or entity that controls the access to the data sets or AI, the data holder or AI holder. In addition, granting a specific right to the data holder is not necessarily a significant creation of new intellectual property, since its creation would be subject to the context of the compulsory licence and thereby only affect the individual parties involved. Consequently, the risk of distorting the intellectual property landscape by introducing a new exclusionary right is considerably higher than the compulsory licence approach.

It therefore appears to be at least conceivable to prefer either not to make any changes to the existing principles of intellectual property law or to consider a selective, individual contractual method in the form of compulsory licensing to balance interests. Particularly interesting about this approach is its opposite direction to traditional approaches. The idea is no longer to create more property rights, but instead to focus more on the perspective of availability for the general public.

One example of more availability is Art. 4 of EU Directive 2019/790 on copyright and related rights in the Digital Single Market. Article 4 provides exceptions and limitations to copyright law to allow for text and data mining. The intention of Art. 4 - and even more so Art. 3 - was to further scientific research and innovation. The need for open access and the advantages of big data analyses were addressed with these inventions. In addition, it seemed legally appropriate to restrict copyright laws to the creative parts of a work. Those elements which themselves are not covered by copyright should be available to the public. While this provision functions as a good example of how to balance the interests between the individual copyright holder and the public domain, it is not generally applicable to AI. First, the provision only covers data within lawfully accessible works. The data sets for networking purposes are not publicly available as they are valuable trade secrets. Furthermore, the term "data mining" is defined to have the purpose of "generating information". ${ }^{153}$ It is unclear whether this allows users to use data mining to create other databases or works, or whether the use is restricted to such research purposes of "big data". Lastly, the provision only exempts reproductions and extractions of the protected material, and creating an AI background database requires substantial modifications of such data.

Hence, Art. 4 is unsuitable as a basis for general availability of AI, although it illustrates very well what a possible solution of the public availability issue may look like.

$\overline{153}$ Art. 2(2) EU Directive 2019/790. 


\section{Conclusion}

Machine learning offers an extraordinary opportunity for smart grid initiatives, as it not only makes it possible to feed renewable energies into a power grid in a meaningful way, but can also enable attractive pricing for users and protect the network against modern cyber-attacks. Such a design of an intelligent energy supply is hardly conceivable without the integration of machine learning.

Both Chinese and Western patent law systems agree that algorithms as such are non-patentable, but with a smart grid algorithm the necessary prerequisite for technicality can be met by integrating AI in a technical system. ${ }^{154}$ Although, considerable uncertainties in the distinction of integrated AI and pure algorithms also exist, the Chinese approach seems to allow for a greater variety of successful patent applications, because the requirements are less narrow. The roots for the political goal of offering more protection for AI inventions can be found in the legal culture of Chinese patent law. Therefore, it is dangerous to follow the Chinese considerations about pure economic incentives. It seems likely that the Chinese approach is more politically driven than truly based on an economic analysis. Furthermore, the lengthy and complex patenting process stands in the way of the speed of algorithms. In all analyzed patent law jurisdictions, the result of a machine learning process in its sole form as an algorithm likely remains unprotected because it lacks the status of a technical invention. The same applies to copyright protection. Protection as a trade secret also harbours inadequacies ${ }^{155}$ and seems unsuitable in relation to the great development efforts and investments. In order to do justice to the specific characteristics of machine learning processes and their economic importance, it makes sense to create an appealing regime in intellectual property law so that specific smart grid solutions can also be available. However, it is unlikely that creating more protection is the only way to achieve this goal. The concept of compulsory licences to serve the interests of the public should be explored in further detail.

Funding Open Access funding enabled and organized by Projekt DEAL.

Open Access This article is licensed under a Creative Commons Attribution 4.0 International License, which permits use, sharing, adaptation, distribution and reproduction in any medium or format, as long as you give appropriate credit to the original author(s) and the source, provide a link to the Creative Commons licence, and indicate if changes were made. The images or other third party material in this article are included in the article's Creative Commons licence, unless indicated otherwise in a credit line to the material. If material is not included in the article's Creative Commons licence and your intended use is not permitted by statutory regulation or exceeds the permitted use, you will need to obtain permission directly from the copyright holder. To view a copy of this licence, visit http:// creativecommons.org/licenses/by/4.0/.

\footnotetext{
154 At least according to the specifications given by the EPO.

155 Hoeren and Münker (2018), pp. 150, 151; Ehringer and Stiemerling (2018), p. 770.
} 


\section{References}

Bahke E (1985) Der Erfinder zwischen Kunst, Wissenschaft und Technik, GRUR, pp 596-605

Barnes D (2010) The incentives/access tradeoff. Northwest J Technol Intellect Prop 9:96-127

Brown N (2018) Artificial authors: a case for copyright in computer-generated works. 20 Columbia Sci Technol Law Rev 1:2-28

China Smart Grid Network Market - Growth, trends, and forecasts (2020-2025)

CNIPA Guidelines for Patent Examination (2014)

CNIPA Guidelines for Patent Examination (2017)

Cohen R, Lemley J (2001) Patent scope and innovation in the software industry. 89 Calif Law Rev 1:37-40

Dornis T (2019) Der Schutz künstlicher Kreativität im Immaterialgüterrecht. In: GRUR, pp 1252-1264

Ehringer P, Stiemerling O (2018) Die urheberrechtliche Schutzfähigkeit von Künstlicher Intelligenz am Beispiel von Neuronalen Netzen. CR 761-768

EPO Guidelines for Examination (2019)

Esmalifalak M et al (2014) Detecting stealthy false data injection using machine learning. Smart Grid IEEE Syst J 11:1644-1652

Examination Guidelines for Patent and Utility Model in Japan (2015)

Fjelland R (2020) Why general artificial intelligence will not be realized. Humanit Soc Sci Commun. https://doi.org/10.1057/s41599-020-0494-4

Fu X (2014) Regenerative medicine research in China: from basic research to clinical practice. Sci China Life Sci 57:155-156. https://doi.org/10.1007/s11427-013-4600-3

Fu L, Zhao H, Guo S (2012) An analysis on the low-carbon benefits of smart grid of China. Phys Procedia 24:328-336. https://doi.org/10.1016/j.phpro.2012.02.049

He J (2011) Daxuesheng Zhishichanquan Jiaoyu Tanxi - Yi Shandongsheng Daxuesheng zhishichanquan Yishi Diaocho wei Jichu [Analysis on the education of intellectual property for college students]. J Shandong Youth Univ Polit Sci 27:27-42

He J (2020) Intellectual property court of the supreme people's court of the People's Republic of China. In: WIPO conversation on intellectual property and artificial intelligence, issue 2: patents: inventorship and ownership, pp 1-12

Hink R (2014) Machine learning for power system disturbance and cyber-attack discrimination. In: IEEE resilient control systems, pp 104-110. https://doi.org/10.1109/ISRCS.2014.6900095

Hoeren T, Münker R (2018) Die EU-Richtlinie für den Schutz von Geschäftsgeheimnissen und ihre Umsetzung. WRP, pp 150-155

IThinkTank (2019) A report on the value and competitiveness of Chinese AI-related inventions. CNR, 27 December 2019

Jänich V (2002) Geistiges Eigentum - eine Komplementärerscheinung zum Sacheigentum? Mohr Siebeck, Tübingen

Jiang C (2016) Machine learning paradigms for next-generation wireless networks. IEEE Wirel Commun 24:98-106. https://doi.org/10.1109/MWC.2016.1500356WC

Landscheidt C, Bethge R (2019) Die Patentierbarkeit "Künstlicher Intelligenz" nach EPÜ. DSRITB, pp 769-778

Lauber-Rönsberg A (2019) Autonome "Schöpfung" - Urheberschaft und Schutzfähigkeit. GRUR, pp 244-253

Leddy M, Marquardt P (2003) The essential facilities doctrine and intellectual property rights: a response to Pitofsky, Patterson, and Hooks. Antitrust Law J 70:847-873

Lederer T (2019) Patentierung im Bereich Künstlicher Intelligenz. GRUR-Prax, pp 152-159

Leistner M, Hansen G (2008) Die Begründung des Urheberrechts im digitalen Zeitalter. GRUR, pp 479-490

Li L, Liu T (2016) How to determine the patentability of inventions relating to computer programs. China Invent Patent 8:102-116

Li D, Sudharman J (2014) Machine-learning aided optimal customer decisions for an interactive smart grid. IEEE Syst J 9:1529-1540. https://doi.org/10.1109/JSYST.2014.2334637

Liu D (2006) The transplant effect of the Chinese patent law. Chinese J Int Law 733-752. https://doi.org/ 10.1093/chinesejil/jm1035

Liu C (2019) A study on the patentability of AI-related inventions. Present day Law Science, pp 4-24

Liu P, Ying L (2006) Woguo Shehui Gongzhong Thishichanquan Yishi Xianzhuang Diaocha Fengxi ji Duice Yanjiu [Survey of Chinese public's IP protection awareness and some recommendations]. China Soft Sci, 103-110 
Liu A, Fan D (2007) Hepatitis B in China. The Lancet 369:1582-1590

McCarthy C et al (1955) A proposal for the Dartmouth summer research project on artificial intelligence, p 48

Meng YJ, Meng TC (2011) Zhishi Jingji Shidai de Daxuesheng Zhishichanquan Yishi he Renzhi Zhuangkuang Yanjiu [A study on university students' awareness and cognition of intellectual property in an era of knowledge-based economy]. J Nanjing Univ Sci Technol, 96-144

Ménière Y, Pihlajamaa H (2019) Künstliche Intelligenz in der Praxis des EPA. GRUR, pp 332-336

Nägerl J, Neuburger B, Steinbach F (2019) Künstliche Intelligenz: Paradigmenwechsel im Patentsystem. GRUR, pp 336-341

National Bureau of Statistics of China (2020) Statistical Communiqué of the People's Republic of China on the 2019 National Economic and Social Development

Ory S, Sorge C (2019) Schöpfung durch Künstliche Intelligenz? NJW 72:710-715

Ozay $\mathrm{M}$ et al (2015) Machine learning methods for attack detection in the smart grid. IEEE Trans Neural Netw Learn Syst. https://doi.org/10.1109/TNNLS.2015.2404803

Papastefanou S (2019) Kommunikation, Kreation und Innovation - Recht im Umbruch? Leipzig, pp 9-28

Peng J (2018) Patenting human embryonic stem cell related inventions in China. Peking

Perry M, Margoni T (2010) From music tracks to Google maps: who owns computer-generated works? Western University Law Publications Paper 10, https://doi.org/10.1016/j.clsr.2010.09.005

Pesch S (2020) Unzureichende Erfinderbenennung bei Angabe künstlicher Intelligenz. GRUR-Prax 84

Schmidt J et al (2019) Recent advances and applications of machine learning in solid-state materials science. NPJ Comput Mater. https://doi.org/10.1038/s41524-019-0221-0

Sharma N, Sharma P, Irwin D, Shenoy P (2011) Predicting solar generation from weather forecasts using machine learning. In: IEEE smart grid communications, pp 528-534

Sheikhi A, Rayati M, Ranjbar A (2015) A cloud computing framework on demand side management game in smart energy hubs. IEEE Innov Smart Grid Technol. https://doi.org/10.1016/j.ijepes.2014.08.020

Simmhan Y, Aman S, Kumbhare A, Liu R, Stevens S, Zhou Q, Prasanna V (2013) Computing in science \& engineering, pp 38-47. https://doi.org/10.1109/MCSE.2013.39

Shoyama R (2005) Intelligent agents: authors, makers, and owners of computer-generated works in Canadian copyright law. Can J Law Technol 4:129-140

So P (2018) Technical elements of machine learning for intellectual property law. Hong Kong

Surden H (2014) Machine learning and law. Wash Law Rev 89:87-98

Tan R (2017) Nongcun gongzhong dui Zhishichanquan de Renzhidu ji Guanzhudu Yanjiu [Research on plural public's awareness of and attention to intellectual property rights]. J Northwest A\&F Univ 17:144-174

Tännsjö R (2007) Why no compromise is possible. Metaphilosophy 38:330-338

Telang R (2014) The market structure for internet search engines. J Manag Inf Syst 21:137-160. https:// doi.org/10.1080/07421222.2004.11045805

Tian J (2003) Shengming Xingshi Zhishi Chanquan ji Guojia Zhengce [Intellectual property right of life form and national policies]. China Agriculture Press, Peking

Turney J (2005) Defining the limits of the EU essential facilities doctrine on intellectual property rights: the primacy of securing optimal innovation. Northwest J Technol Intell Property 3:179-201

U.S. Energy Information Administration (2020) Country analysis executive summary: China

USPTO (2019) Revised patent subject matter eligibility guidance

Wang N (2016) Shehui Gongzhong Zhishichanquan Renzhidu Diaocha yu Fenxi ji Silu Tantao [The survey, analysis, and discussion on public perceptions of IP]. Guang Xi, Modern Business, pp 175-201

Wang J (2017) On the legal determination of AI-generated contents in the copyright law. Science of Law, pp $150-174$

World Intellectual Property Organization (2019) Technology trends 2019: artificial intelligence. WIPO 85

Yin D (2011) Zhongguo Zhuanlifa Xiangjie [Introduction to the patent law of China]. Intellectual Property Press, Hong Kong

Yu Y et al (2012) The smart grids in China—a review. MDPI Energies. https://doi.org/10.3390/ en5051321

Publisher's Note Springer Nature remains neutral with regard to jurisdictional claims in published maps and institutional affiliations. 